\title{
Parents' Perspectives of Distance Education during Crises: The Benefits and Disadvantages
}

\author{
Salem Alalwani \\ Department of Education and Psychology, \\ College of Education, University of Hafr Al-Batin, \\ Al Jamiah, Hafar Al Batin 39524, \\ Saudi Arabia
}

DOI: https://doi.org/10.36941/jesr-2022-0041

\begin{abstract}
This study explored parents' views on the benefits and disadvantages of distance learning during crises. They have been informed about a school platform called Madrasti which has an electronic educational system. The study used the descriptive research method and open interviews on a sample of 28 parents (pairs of fathers and mothers) of 14 Saudi families with children at the primary education in different cities in the Kingdom of Saudi Arabia at the second term of 2020-2021. Study results indicated economic, social, and educational benefits, such as saving school fees, family spending with children, and students acquiring e-learning skills. However, disadvantages were also noted, such as long hours spent on the platform, slow and intermittent Internet connection, poor computer skills among students, and teachers' poor class management. Results of the study indicated some positives, economic, social, and educational, such as saving school fees, Family becomes spending more time with children, students learning skills in e-learning. In contrast, there are some negatives such as the platform's time being too long, weakness, and constant interruption of the Internet. Weakness of using computer skills for some students, and some teachers have weakness in class management. Thus, the study suggests educational, economic, social, and technical requirements to improve the effectiveness of the Madrasti platform. Additionally, future research must explore social problems faced by Saudi families during distance learning and the extent of students' satisfaction with education through the Madrasati educational platform.
\end{abstract}

Keyword: Distance education, Crisis, Parents' perspective, COVID-19

\section{Introduction}

Crises are unexpected events that change the status quo. Recently, the world has witnessed adverse repercussions of the coronavirus pandemic on all fields and sectors worldwide. Countries have started to overcome the spread of the pandemic and deal with it in various ways following experienced countries and competent international organizations. Education is one of the sectors that are seriously affected by the pandemic as most countries have completely locked down educational institutions and have considered other ways to prevent students' backwardness in educational attainment. In the light of that, countries have to manage the educational process in different ways that prevent interruption of education and students' backwardness on joining different educational 
institutions. The Kingdom of Saudi Arabia is one of the countries that followed therecommendations of the World Health Organization. The country activated crisis management plans, including the adoption of distance learning methods and different tools as a suitable choice, especially after the educational disruption of approximately 6 million Saudi students (Ministry of Education, 2021). The Ministry of Education initiated the Madrasti digital platform for all educational stages as an alternative to face-to-face school attendance. The Madrasti platform is a prominent national project in which all financial and human resources were exerted. For primary, middle, and secondary education students, the school day for primary was set in the afternoon from 3:00 to 7:30 when their families return from work, thus allowing them to participate with the children in the educational platform (ibid). Parents believe that their children can gain benefits from distance education, such as self-learning and e-learning skills, though they face challenges, such as poor direct communication and social relation skills. According to Stites et al. (2021), parents reported few opportunities for social-emotional engagement and that, if distance learning continues, mathematics and social courses and teachers' training will need further consideration. Certain studies have indicated that 'parents satisfaction with the learning process depends on many factors, including teaching eligibility and quality and content of education; distance learning during the pandemic has many problems associated with these factors (Bokayev et al., 2021). Additional studies have noted that difficulties in completing distance learning tasks at home as most children could not complete these tasks independently. Moreover, parents without online learning knowledge were dissatisfied with distance learning during the COVID-19 pandemic (Eva \& Kerry, 2021). With schools' suspension, parents' educational responsibilities have increasingly become important. Stay-at-home parents must be knowledgeable about distance learning while managing household responsibilities, whereas those who work outside have to support their children in distance learning while working at the office. Nevertheless, parents will consequently realise the benefits of distance education, though they will face certain problems in the process. Al-Khamisy (2020) discussed the education system during the pandemic and bridging the gap between home and school. He analysed conditions and facts after the emergence of the pandemic and the implications that led to disturbing stable social systems, including the traditional educational system. Particular studies discussed COVID-19 as the main reason for the digital transformation of education and as an evaluation test that aims to survey opinions during distance learning at the climax of the pandemic. Study results showed that e-learning will continue to grow significantly after the pandemic and that e-learning is an indispensable way of learning during a crisis (Mladenova et al., 2020). Almustafa (2021) discussed the effectiveness of distance learning in teaching students with special needs in light of the pandemic. The study was conducted from the perspective of their families, teachers, and their attitudes towards e-learning. Results showed that the families of students with special needs demonstrated positive attitudes towards distance learning in aspects such as dealing with the means of technology and various teaching methods. However, negative outcomes were also observed, such as increasing the burden on the family and unfair evaluation. Öçal et al. (2021) studied distance education amid the COVID-19 pandemic and evaluated parents, children, and teachers' competencies. They noted that the education system is one of the areas severely affected by the pandemic as teachers, students and parents exhibited profound changes. Bokayev et al. (2021) studied distance learning in Kazakhstan to estimate parents' satisfaction of educational quality during the COVID-19 pandemic and found that parents' age and family income level are positively correlated with the parents' satisfaction level with the provided distance education, whereas the number of children in a family is negatively correlated. Stites et al. (2021) studied preschool parents' views of distance learning during the COVID-19 pandemic. Results of the online survey indicated the types of activities parents engaged in and the challenges they face in preschool distance learning, including the types of resources they needed. Bansak and Starr (2021) discussed the pandemic shocks to education supply and how 200,00o U.S. households dealt with the sudden shift to distance learning. Results showed that parents needed to mediate and spend significant considerable time helping their children continue to distance learning, though they faced significantly more problems with computer and Internet access. Moreover, Bakker and Wagner 
(2020) stated that many students during the COVID-19 period had no access to resources and could not engage in online education, leading to inequality. In addition, Eva et al. (2021) explored parents' views on kindergarten and primary school students' distance learning experience during the COVID19 pandemic and found that most children encountered difficulties in completing distance learning tasks at home. Moreover, parents without online learning knowledge were dissatisfied with distance learning. According to certain studies, parents believe that when their children's learning is controllable and they are satisfied with the learning offered by the school, their parenting stress decreases and parental involvement increases (Lau et al., 2019). Thus, when building e-learning platforms, the school must be aware of 'parents and the community's views. Dong et al. (2020) noted that, parents had negative attitudes towards distance learning. Other studies have found that parents in distance learning are influenced by several factors, such as educational levels, socioeconomic status, infrastructure, and technological resources (Rideout \& Katz, 2016; Jonsdottir et al., 2017).

To the best of our knowledge, many local studies investigated distance learning and its tools, student satisfaction, and teachers' performance during the COVID-19 pandemic. However, only a few studies discussed parents' views on distance education. Examining parents' views on primary school students' learning experience, the benefits and disadvantages of distance learning and the support they need is important. Accordingly, this study discusses the views and trends of families about the educational platform during the pandemic and recognises its positive and negative impacts as they deal with this platform daily. The findings of the current study address the gaps in research using a sample of primary school parents Thus, this study aimed to address the following questions:

1. What is the school's educational platform?

2. What are the parents' perceived benefits of distance education represented in the school platform?

3. What are the parents' perceived disadvantages of distance education represented in the school platform?

4. How can the distance education platform be reformed according to the families' responses?

\section{Limitations of the Study}

1. Participants: Study participants included only Saudi families with primary children using the Madrasti educational platform.

2. Time: This study was applied to the second term of the school year 2020-2021 only.

3. Place: The Kingdom of Saudi Arabia has many cities, including Riyadh, Jeddah, Medina, Yanbu, Taif, Dammam, and Hafr Al-Batin.

\section{Methodology}

This study employed the descriptive approach based on the research questions. Interview models are classified into structured, unstructured, and semi-structured (Creswell, 2009). The current study selected the structured interview, where all questions are predetermined by the researcher before conducting the interview. This study also used open interviews to collect information or data. It is a technical relationship between the researcher and the research sample which is dominated by comfort and mutual trust aiming to collect information that helps in interpreting and solving problems (Suleiman, 2010).

\section{COVID-19 Pandemic and Distance Learning (Madrasti Platform)}

The COVID-19 pandemic imposed lockdowns in several countries for a long time, affecting economic, social, political, and cultural fields. Particularly, the pandemic has caused the biggest interruption in educational systems throughout history. Approximately 1.6 billion students in more than 190 countries across all continents have suffered educational disruption as school lockdowns affected $94 \%$ of students 
worldwide (UNESCO, 2020). The pandemic has also worsened educational differences as many children and youths were prevented from continuing their education. UNESCO estimated that the economic impact of the pandemic may lead to the dropout of 8.23 million children and youths from pre-primary to high school education and may affect new students in the next year (United Nations, 2021). One of the reports mentioned that approximately 100 million students in the Arab region are now out of school and that school lockdown due to the pandemic may expose poor children to risks of dropout (ESCWA, 2021). Saudi Arabia is one of the countries greatly affected by the pandemic. In response, the country issued a decision to close schools and activated crisis management plans, including adopting distance learning and different tools as a suitable choice, especially after the educational disruption of approximately 6 million Saudi students (Saudi Ministry of Education, 2021). The world today lives in the age of interconnected technology, where billions of computers are connected. Various digital devices have transformed several concepts and processes in social fields, such as economics and education. Online teaching helps students and provides them with many resources and scientific methods. Distance education achieves many goals, including self-learning, recent technology developments, and good communication skills among students (Yuliang, 2005). Moreover, distance education offers learners wide options, eliminating certain restrictions (Adika, 2019).

The Madrasti is an educational platform that uses an electronic educational system. This platform achieves the educational objectives of a syllabus and curriculum to cope with education's present and future digital requirements. The Ministry of Education of the Kingdom of Saudi Arabia developed this digital platform for all academic levels as an alternative for face-to-face attendance at school during the COVID-19 pandemic (Saudi Ministry of Education, 2021). The Madrasti is a prominent national project in which the Ministry of Education has exerted significant financial and human resources. The platform provides varied and developed educational channels for affective connection between beneficial male and female students, their parents, teachers, schools leaders, and educational supervisors. The platform also allows adding books and curriculums for all academic levels, various educational and interactive paths, and a bank of nearly 100.000 electronic questions for all syllabuses (Saudi Ministry of Education, 2021). This platform is divided into two periods: from 9:00 a.m. to 2:00 p.m. for the middle and high school and from 2:00 p.m. to 8:00 p.m. for the primary school. It has also digital platforms which contain various educational contents and electronic lessons of the teachers (Madrasti Platform, 2020). Moreover, the platform allows learning English for all levels, club mathematics, traffic safety, and other educational resources (Madrasti Platform, 2020).

\section{Field Study}

The field study aims to recognise parents' perspectives of Madrasti educational platform. The Saudi Ministry of Education has accredited Madrasti for teaching students during the COVID-19 pandemic. The field study included interviews with 14 families of the students' parents. The sample comprises 28 parents (pairs of father and mother) from 14 Saudi families with children in primary education in different cities of the Kingdom of Saudi Arabia. Each interview lasted for approximately 5 minutes and comprised two main questions. The aim was to understand the parents' perspectives on the educational platform. In the light of responses collected from the study sample, a qualitative analysis was performed on the responses collected. Table 1 below presents the results.

Table 1: Residence type

\begin{tabular}{|c|l|c|c|}
\hline SN & Residence type & No. & $\%$ \\
\hline 1 & Apartment & 4 & $28,57 \%$ \\
\hline 2 & House & 10 & $71,42 \%$ \\
\hline
\end{tabular}

Table 1 above shows that $71,42 \%$ and $28,57 \%$ of the study sample reside in a house and an apartment, respectively. A thesis may affect Saudi families' answers about the study subject. Students who reside 
with families in big houses, where they have sufficient spaces and rooms, have much independence and privacy in distance learning, whereas students who live with families in small apartments have a lower level of privacy and independence.

Table 2: Family income

\begin{tabular}{|c|l|c|c|}
\hline SN & Family income & Number of families & $\%$ \\
\hline 1 & Less than SAR 2000 & - & - \\
\hline 2 & SAR 2000-4000 & 2 & $14,29 \%$ \\
\hline 3 & SAR 4000-600o & 2 & $14,29 \%$ \\
\hline 4 & SAR 60oo-8000 & 2 & $14,29 \%$ \\
\hline 5 & SAR 80oo-10000 & 4 & $28,57 \%$ \\
\hline 6 & More than SAR 10000 & 4 & $28,57 \%$ \\
\hline
\end{tabular}

Table 2 above shows that family income levels ranging SAR 2000-400o, SAR 400o-60oo, SAR 80oo10000 , and above SAR 10000 are approximately $14,29 \%, 14,29 \%, 28,57 \%$, and $28,57 \%$ of the study sample, respectively. These results indicate that family income may play a big role in the distance learning environment which requires expanding primary equipment used for communication, such as computers. High-income families may not complain about these requirements, whereas low-income families may find difficulty in providing means of communication for their children, as mentioned by certain low-income families during the interview.

Table 3: Number of family members

\begin{tabular}{|c|l|c|c|}
\hline SN & Number of family members & No. & $\%$ \\
\hline 1 & $2-4$ & 2 & $14,29 \%$ \\
\hline 2 & $5-7$ & 10 & $71,42 \%$ \\
\hline 3 & $8-10$ & 2 & $14,29 \%$ \\
\hline 4 & More than 10 & - & - \\
\hline
\end{tabular}

According to Table 3 above, families with 2-4, 5-7, and 8-10 members comprise $14,29 \%, 71,42 \%$, and $14,29 \%$ of the study sample, respectively. The number of family members may affect children's educational level. Small families can significantly concentrate on their children and provide them with psychological, social, and educational needs, whereas big families may not observe all their children due to financial distress in providing their children's needs. These responses were observed from the interviews of Saudi families.

Table 4: Family's educational level

\begin{tabular}{|c|l|c|c|}
\hline SN & Educational level & No. & \% \\
\hline 1 & Bachelor & $\mathbf{1 2}$ & $42,85 \%$ \\
\hline 2 & Secondary & 8 & $28,57 \%$ \\
\hline 3 & Middle & 2 & $7,14 \%$ \\
\hline 4 & Primary & 6 & $21,49 \%$ \\
\hline
\end{tabular}

Table 4 above shows that $12(42,85 \%), 8(28,57 \%), 2(7,14 \%)$, and $6(21,49 \%)$ individuals in the study sample have a bachelor's degree and are in the secondary, middle, and primary school education, respectively. In addition, parents' educational level demonstrates convergence, except for two families. In the first family, the father and mother have a bachelor's degree and secondary educational attainment, respectively. In the second family, they had had middle-level education and bachelor's degree, respectively.

The educational level of the family plays a major role in teaching the children, evaluating their 
education, and recognising the basics of distance learning and the skills it requires. Families with high educational attainment perform better than families with middle and low educational levels. This finding is indicated in the responses of the study sample. Certain that studies showed parents with a college education tend to spend more time helping children with homework than parents with a lower educational level (Bansak \& Martha, 2020). The study presented the following questions to Saudi families regarding the benefits and disadvantages of the Madrasti educational platform:

1. From your perspective, what are the benefits of the Madasti educational platform?

2. From your perspective, what are the disadvantages of the Madasti educational platform?

To address the first question, the researcher performed a qualitative analysis of the responses of the study sample using the NVivo program. Figure 1 below illustrates the finding of the analysis.

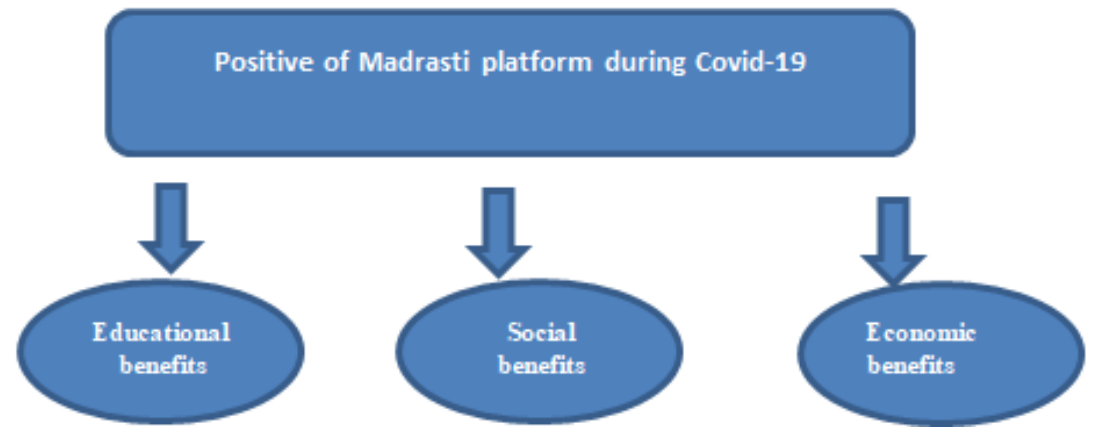

Figure 1: Benefits of the Madrasti platform during the COVID-19 pandemic

Figure 1 above and the interview responses show that most responses are centred on certain benefits (economic, social, and educational), which have positive impacts on student achievement:

Economic benefits (include savings from the following)

- School fees

- School transportation

- Stationery

- Clothes for school

Social benefits

- Parents can attentively follow up on children's lessons daily.

- Children can have meals with their family at home regularly.

- Family can spend more time with children.

- Children are constantly under parental control.

- The distance education system can protect children from bad friends.

Educational benefits

- Children spend less time watching TV.

- Students learn e-learning skills.

- Students learn self-learning skills.

- Parents can evaluate teachers and thus distinguish between professional and unprofessional ones.

- Parents can evaluate their children's educational performance consciously.

Regarding the second question, the researcher performed a qualitative analysis of the responses of the study sample using the NVivo program. Figure 2 below illustrates the results. 


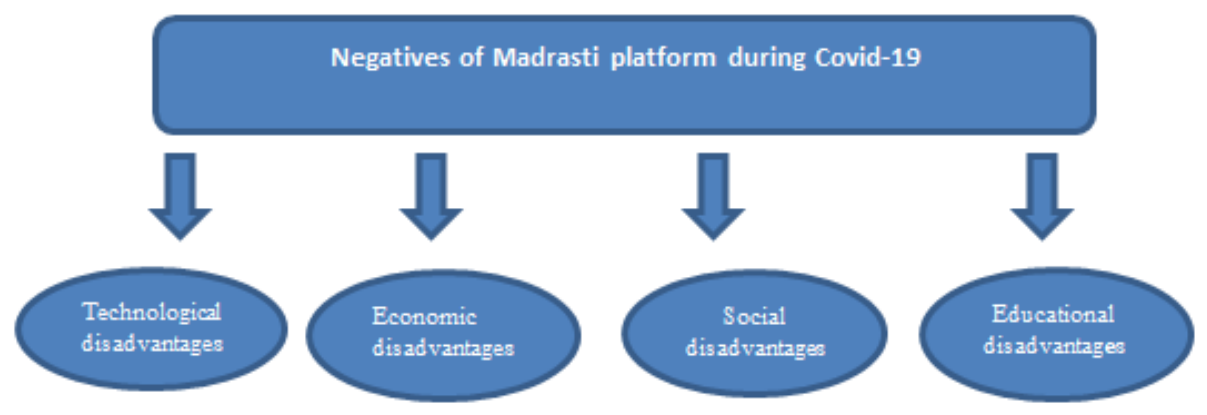

Figure 2: Disadvantages of the Madrasti platform during the COVID-19 pandemic

Figure 2 above and the interview results show that most responses are centred on certain disadvantages (economic, social, educational, administrative, technological, psychological). These disadvantages have negative impacts on the effectiveness of the Madrasti platform and its performance on students as follows:

\section{Educational disadvantages}

- Other children attend the Madrasti platform on behalf of their siblings.

- Students open the camera to see their friends.

- Teachers are late for their class.

- Teachers are absent at their classes.

- Certain teachers have poor class management.

- Students talk to each other at the platform regarding issues not related to the educational content.

- Students are busy with small talks in the absence of the teacher.

- The platform requires long hours, especially for families with children in different educational stages.

- Students have poor concentration with the teacher during the lesson on the platform.

- Children play electronic games during the lesson time.

- Parents (or other family members assisting the children) are not confident to face the camera during the lesson.

- Teachers face difficulty in following up with students to acquire the skills in the primary stage.

- The platform is not suitable for primary school students.

- Children ask their parents to complete the exercises regularly for them.

- Direct education performs better than distance education.

Technological disadvantages

- Weak and constant intermittent Internet connection.

- Poor computer skills among students.

- Background noises of students' families.

- Rampant cheating in Madasti platform.

- Technical glitches in the platform.

\section{Economic disadvantages}

- High Internet costs.

- The difficulty to provide a computer to each student in the family.

- Excessive demand for a private teacher at home.

Social disadvantages

- Difficulty receiving guests at home because the families are preoccupied with their children. 
- Failure to perform certain household chores because of being busy with the platform.

- The duties required in the platform have increased the parents' burdens even in time of rest.

- Certain students are not confident to participate in the platform.

In this study, parents have optimistic and pessimistic perspectives of the educational platform in terms of economic, social and educational aspects. For example, the study found relationships between parents' responses and their education, residence and income variables. For instance, lowincome families referred that the electronic platform may help reduce school expenses, such as transportation and school materials. However, they also referred to certain obstacles, such as insufficient computers, the lack of Internet access, high Internet cost and the need for a private teacher, whereas high-income families did not mention these factors. These results are similar to Öçal et al. (2021) who indicated concerns about the inequality between students as certain students have no access to online resources. Garcia et al. (2020) discussed that students in higher-income households have higher access to electronic devices, such as computers and tablets, and high-speed Internet. Therefore, unequal access to resources to support distance learning may exacerbate student inequality (Bansak \& Starr, 2021).

Moreover, families with high educational attainment stated that they could evaluate the teacher and student's performance in the educational process. They also have the skills required for distance learning contrary to families with a low educational level. This finding is consistent with Sonnenschein et al. (2014) who discussed that parents note that teachers are not well trained and have no access to appropriate technology. Moreover, Bansak and Starr (2021) noted that lesseducated parents face difficulties in distance learning and Internet access. In their responses to the social dimension, small families stated that they could spend more time with their children and can observe them constantly through their study at the platform, whereas big families did not mention this concern. This finding may be because small families have more social integrity and social relations than big families. Other families who reside in apartments have also discussed that they have social problems, such as the difficulty of receiving guests at home because of their children's preoccupation with the platform. In contrast, families residing in separate houses did not address this issue, which may be due to limited space. Families discussed that conventional education is better than distance education. Certain studies have indicated that parents have a negative view of distance education (Dong et al., 2020). In addition, Stites et al. (2021) noted that distance learning is not effective for children.

\section{Conclusion and Recommendations}

This study discussed the Madrasti platform and the efforts of the Ministry of Education in the Kingdom of Saudi Arabia to implement distance learning in light of the COVID-19 pandemic. The study has also discussed Saudi families' positive and negative opinions on the Madrasti platform. The results indicated numerous economic, social, and educational benefits, such as savings in transportation, stationary, and school clothes. Distance learning helped families to follow up children's lessons daily, spend more time with them and avoid dealing with students with bad behaviour. Students were constantly controlled by the family. Through the Madrasti platform, Saudi families could also evaluate teachers, identify their capacities and evaluate their academic performance continuously. However, technical, economic, social, and educational disadvantages were also noted: (1) poor class management of teachers, (2) students logging in through their friends' accounts, (3) teachers' absences, (4) lengthy lesson time at the platform for families with children in different educational stages, (5) weak and intermittent Internet connection, especially in small towns and villages, (6) poor computer skills among students, (7) costly electronic devices and Internet subscriptions, (8) difficulty receiving guests because of the preoccupation of the family with their children at the educational platform, (9) prevalent cheating among students, (10) increased family burden due to homework in the platform, (11) students' lack of concentration with the teacher and 
(12) other negative factors mentioned during the interviews. The study results are similar to previous studies. For instance, Aliyyah et al. (2020) stated that parents' poor Internet literacy affected children's technical learning. Therefore, other students could not access online resources (Öçal et al., 2021). In addition, Rideout and Katz (2016) and Jonsdottir et al. (2017) observed that parents in distance learning are influenced by several factors, such as educational levels, socioeconomic status, infrastructure, and technological resources. The study showed that the family is an important partner of the school in teaching children, though families who are not accustomed to distance learning carry additional burdens that were not handled before. Therefore, they need to deal with this situation positively.

This study suggests the following requirements to improve the effectiveness of the Madrasti platform and thus avoid the disadvantages:

\subsection{Educational requirements}

The Ministry of Education and related authorities should provide teachers (male or female) with continuous professional training and development on various skills and activities, particularly digital and administrative skills for distance learning to eliminate the disadvantages mentioned by the study participants. Training should be provided to Saudi families about the skills required for distance learning, particularly using the Madrasti educational platform, and other educational and technical skills that help in expanding the partnership between schools and homes to avoid challenges. Furthermore, continuous activation of discussion panels and parents' councils, in person or by default, greatly help in solving problems with children faced by families. External distractions to the educational process were also stated by the participants, such as students opening devices' cameras and playing electronic games during class. Therefore, this condition requires continuous awareness of the importance of time spent on school platforms, encouraging students to engage in the educational process in a focused manner, and encouraging Saudi families to monitor and support their children to focus and interact during the educational process.

\subsection{Economic requirements}

The economic requirements highlight the importance of increasing the distance learning budget to provide continuous training and development for teachers and various human resources and Saudi families. Moreover, low-income families face challenges in providing devices, such as tablets and computers, to all their children. Thus, the Ministry of Education needs solutions to help these families in different ways, such as providing them with devices for free, at a discounted price, or through installments by signing partnerships with technology companies. The provision of an educational corner inside the home may also help families and students to acquire educational subjects in an engaging and beneficial way.

\subsection{Social requirements}

These requirements are attributed to the social problems faced by families and children alike. Families may face some social problems, such as the length of time spent on the platform, especially families with children in different educational stages (primary, middle, secondary). The platform time has been divided into different times in the morning and evening, which causes concern for Saudi families in fulfilling their various social obligations. Accordingly, the study considers the importance of considering the same school day for all primary school students, though this situation may lead to Internet traffic on the educational platform or on students' devices. Nevertheless, these obstacles may be addressed by improving the Internet infrastructure and providing devices for each student at home. In addition, the issue of social acceptance of certain Saudi families for distance learning is another social problem. Other families perceive that distance learning does not serve the same 
purpose in conventional education and that lessons and homework are easier and lack seriousness. Hence, schools and the Ministry of Education should provide continuous awareness and appropriate training for students' parents about distance learning skills and their multiple advantages. Moreover, class differences between students must be eliminated by providing equal educational opportunities for all students. This approach will particularly help students in remote areas and small villages facing technical problems, such as continuous Internet outages and intermittent or poor Internet connection, and those who lack devices. The Ministry of Education must address these concerns and compensate for educational losses appropriately, such as teaching children emotional and social skills that are taught only from their schools. Therefore, training programs and the messages directed by schools and training centers for these aspects are necessary.

\subsection{Technical requirements}

Excellent infrastructure for various means of communication and continuous technical support for the technical problems faced by families and students are required. This approach will contribute to improving the performance of the Madrasati educational platform and virtual education quality.

Therefore, the study suggests paying attention to these requirements and providing them to improve the education quality of the Madrasati educational platform, effectively contribute to providing students with distinguished educational content and help Saudi families in pursuing their children's education in a flexible and accessible manner. Finally, the researcher recommends conducting additional studies that address the social problems faced by Saudis families during distance learning. The study also recommends the importance of exploring the extent of students' satisfaction with education through the Madrasati educational platform.

\section{References}

Adika, S. (2019). Recent trends in educational technology for people with special needs: auditory and visual impairment as a model. The Arab Journal of the Sciences of Disability and Giftedness, The Arab Foundation for Education, Science and Arts, 1(6), 89-112

Aliyyah, R. R., Rachmadtullah, R., Samsudin, A., Syaodih, E., Nurtanto, M., \& Tambunan, A. R. S. (2020). The perceptions of primary school teachers of online learning during the COVID-19 pandemic period: A case study in Indonesia. Journal of Ethnic and Cultural Studies, 7(2), 90-109. https:// doi.org/10.29333/ejecs/388

Al-Khamisy, S.. (2020). Education in the time of Corona (Covid-19), Bridging the gap between home and school. International Journal of Research in Educational Sciences, Vol. 3, 4, 51-73

Al-Thabit, L. M. (2020). How did the Kingdom of Saudi Arabia face the challenges of education in light of the Corona pandemic? Journal of the Egyptian Society for Reading and Knowledge, Faculty of Education, Ain Shams University, No. 228, 91-113.

Almustafa, G. (2021). The effectiveness of distance learning in teaching students with special needs in light of the Covid 19 from the point of view of their families, teachers, and attitudes towards it in the State of Qatar, Educational Journal, University of Jordan, (48)2, 353-367

Bakker, A., \& Wagner, D. (2020). Pandemic: lessons for today and tomorrow? Educational Studies in Mathematics, 104(1), 1-4. https:// doi. Org/10. 1007/s10649-020-09946-3

Bokayev, B., Torebekova, Z., Davletbayeva, Z., \& Zhakypova, F. (2021). Distance learning in Kazakhstan: estimating parents' satisfaction of educational quality during the coronavirus. Technology, Pedagogy and Education, 30:1, 27-39, DOI:10.1080/1475939X.2020.1865192

Bowen, G. (2009). Document analysis as a qualitative research method. Qualitative Research Journal, 9, 27-40

Bansak, C., \& Starr, M. (2021). Covid-19 shocks to education supply: how 200,00o U. S. households dealt with the sudden shift to distance learning, Rev Econ Household (2021) 19:63-9o https://doi.org/10.1007/s11150-020-09540-9

Dong, C., Cao, S., \& Li, H. (2020). Young children's online learning during COVID-19 pandemic: Chinese parents' beliefs and attitudes. Children and Youth Services Review, 118, 1-9. https://doi.org/10.1016/j.childyouth.2020.105440

El-Gawhari, H. K. A. (2020). Awareness of faculty members at Prince Sattam bin Abdulaziz University using the elearning platform in light of the outbreak of the Covid 19 virus and their attitudes towards learning by the survey. Journal of Educational and Psychological Sciences, Vol. 4, 46, 40-63 
ESCWA (2021). Brief Policy. Retrieved July 20, 2021, from https://afsd2021.unescwa.org/sdgs/pdf/covid-19/ar/10impact-covid-19-young-peoplearab-region-arabic.pdf

Lau, E. Y. H., \& Lee, K. (2021). Parents' views on young children's distance learning and screen time during COVID-19 class suspension in Hong Kong. Early Education and Development, 32:6, 863-88o, DOI: 10.1080/10409289.2020.1843925 To link to this article: https://doi.org/10.1080/10409289.2020.1843925

Garcia, E., Weiss, E., \& Engdahl, L. (2020). Access to online learning amid coronavirus is far from universal, and children who are poor suffer from a digital divide. Economic Policy Institute, April 17. https://www.epi.org/blog/access-to-online-learning-amid-coronavirus-and-digital-divide/

John W. Creswell, Cheryl N. Poth. (2018). Qualitative Inquiry and Research Design: Choosing Among Five Approaches (2nd ed.). SAGE Publication Ltd, USA.

Jónsdóttir, K., Björnsdóttir, A., \& Baeck, U. K. (2017). Influential factors behind parents' general satisfaction with compulsory schools in Iceland. Nordic Journal of Studies in Educational Policy, 3(2), 155-164. https://doi.org/10.108o/20020317.2017.1347012

Stites, M. L., Sonneschein, S., \& Galczyk, S. H. (2021). Preschool parents' views of distance learning during COVID19. Early Education and Development, 32:7, 923-939, DOI: 10.1080/10409289.2021.1930936

Madrasti Platform, Ministry of Education (2020). Retrieved March 12, 2021, from https://schools.madrasati.sa

Ministry of Education, Kingdom of Saudi Arabia (2021). Retrieved 20 September 2021, from https://www.moe.gov.sa/ar/news/Pages/mn-2020-876.aspx 22-8-2020

Mladenova, T., Kalmukov, Y., \& Valova, I. (2020). Covid 19 - A major cause of digital transformation in education or just an evaluation test. TEM Journal, 9(3), 1163-1170

Rideout, V. J., \& Katz, V. S. (2016). Opportunity for all? Technology and learning in lower-income families. A report of the families and media project. The Joan Ganz Cooney Center at Sesame Workshop

Rizun, M., \& Strzelecki, A. (2020). Students' acceptance of the COVID-19 impact on shifting higher education to distance learning in Poland. International Journal of Environmental Research and Public Health, 17(18)

Safr, A. H. (2020). Obstacles to education and distance learning in public education in the State of Kuwait during the outbreak of the new Coronavirus pandemic, Covid 19, from the viewpoint of faculty members at Kuwait University, Educational Journal, Sohag University, Vol. 79, 2057-2104

Sonnenschein, S., Stapleton, L. M., \& Metzger, S. R. (2014). What parents know about how well their children are doing in school. The Journal of Educational Research, 107(2), 152-162. https://doi.org/10.108o/00220671.2013.788987

Suleiman, S. M. (2010). Data collection tools in educational and psychological research, World of Books, Cairo, p. 163

Tao, S. S., Lau, E. Y. H., \& Yiu, H. M. (2019). Parental involvement after the transition to school: Are parents' Expectations matched by experience? Journal of Research in Childhood Education, 33(4), 637-653. https://doi.org/10.1080/02568543.2019.1653409

Öçal, T., Halmatov, M. \& Ata, S. (2021). Distance education in COVID-19 pandemic: An evaluation of parent's, child's and teacher's competencies. Education and Information Technologies, https://doi.org/10.1007/s10639021-10551-x

UNESCO. (2020). Educational response to COVID-19. Retrieved 20 March 2021, from https://ar.unesco.org/covidig/educationresponse

United Nation. (2021). Policy Brief: Education during COVID-19 and beyond Retrieved July 20, 2021, from https://www.un.org/sites/un2.un.org/files/policy_brief_education_during_covid

Yuliang, L, (2005). Impact of online instruction on teachers' learning and attitudes toward technology integration. Journal of Distance Education, 12(2), 63-72 